\title{
Transcriptional regulation of multiciliated cell differentiation
}

Michael Lewis and Travis H. Stracker*

Institute for Research in Biomedicine (IRB Barcelona), The Barcelona Institute of Science and Technology, C/ Baldiri Reixac 10, Barcelona 08028, Spain.

*Corresponding author: travis.stracker@irbbarcelona.org

Running title: Making multiciliated cells

Word count:

10,049 (all text, legends and references, excluding abstract and Table S1) 


\begin{abstract}
:
Multiciliated cells (MCC) project dozens to hundreds of motile cilia from the cell surface to generate fluid flow across epithelial surfaces or turbulence to promote the transport of gametes. The MCC differentiation program is initiated by GEMC1 and MCIDAS, members of the geminin family, that activate key transcription factors, including p73 and FOXJ1, to control the multiciliogenesis program. To support the generation of multiple motile cilia, MCCs must undergo massive centriole amplification to generate a sufficient number of basal bodies (modified centrioles). This transcriptional program involves the generation of deuterosomes, unique structures that act as platforms to regulate centriole amplification, the reactivation of cell cycle programs to control centriole amplification and release, and extensive remodeling of the cytoskeleton. This review will focus on providing an overview of the transcriptional regulation of MCCs and its connection to key processes, in addition to highlighting exciting recent developments and open questions in the field.
\end{abstract}

\title{
Keywords:
}

Multiciliated cells; E2F4; E2F5; GEMC1; MCIDAS; FOXJ1; MYB; p73; NOTCH; AHR; TRRAP; CCNO; CDC20B; centriole; basal body; airway; ependyma; germline; ciliopathy; infertility; hydrocephalus

\section{Abbreviations}

MCC:

Multiciliated cell

GMNC: $\quad$ GEMC1, Geminin coiled-coil containing protein 1

MCIDAS: $\quad$ Multicilin, Idas

GMNN: Geminin

Air liquid interface: ALI

Basal body: $\quad$ BB

Radial Glial Cells: $\quad$ RGC

Pericentriolar material: PCM

\section{Highlights}

- GEMC1 and MCIDAS control multiciliated cell differentiation in a stepwise manner.

- p73 plays a major role in multiciliogenesis.

- Multiciliated cells activate a cell cycle program to regulate centriole amplification.

- PLK4, mother centrioles and deuterosomes are not strictly required for multiciliogenesis.

- Centriole numbers scale to cell surface area. 


\section{Multiciliated cells in vertebrates}

Multiciliated cells (MCCs) are specialized epithelial cells that project multiple motile cilia required for respiratory, reproductive, renal and brain functions in many vertebrates[1]. In humans, MCCs are present in the ependyma and choroid plexus of the brain to direct the flow of cerebrospinal fluid, the airways to clear mucus and pathogens, and in the efferent ducts and oviducts for spermatozoa and egg transport, respectively. Depending on the tissue, dozens to hundreds of motile cilia are generated per MCC that can beat in a coordinated, directional manner or generate turbulence through whip-like movements[1,2].

The process of MCC differentiation, or multiciliogenesis, requires the activation of a unique transcriptional program that specifies cell fate and allows the massive amplification of centrioles; barrel-shaped, microtubule based organelles that dock at the cell surface with other factors to provide a basal body (BB) required to support the generation of the ciliary axoneme[3]. As several recent reviews have covered different aspects of multiciliogenesis in great detail[1,3-10], here we will focus on providing an overview of the transcriptional regulation of multiciliogenesis and how it connects to key cellular processes. In addition, we will highlight recent advances in our understanding of other cell biological aspects of MCC development and the consequences of their dysfunction.

\section{MCC specification: Notch and the Geminin family proteins}

The inhibition of Notch signaling has emerged as a consistent early event in MCC differentiation from the study of frog skin, zebrafish pronephros and murine ependymal, fallopian tube (oviduct) and airway epithelia (Figure 1) [11-18]. The precise details of Notch regulation remain unclear in all cases but the Mir-34/449 family of miRNAs has been implicated in Notch inhibition in frogs, zebrafish and mice and this miRNA family plays redundant roles in MCC formation in several tissues, including the brain, airway and male germline[2,11,13,19-23]. In the murine airway, progenitor cells give rise to secretory (Clara) or MCC lineages in a Notch dependent manner[24]. Genetic or pharmacological inhibition of Notch causes the trans-differentiation of secretory cells into MCCs, demonstrating a central role for Notch inhibition in initiating the MCC differentiation program in the airway[15].

The full effects of Notch inhibition on transcription have not been clearly elucidated at early steps of MCC differentiation, but fate decisions following Notch inhibition are controlled by the interplay between the Geminin family proteins; Geminin (encoded by GMNN), GEMC1 (Geminin coiled-coildomain containing protein 1, encoded by GMNC) and MCIDAS (Multicilin (MCI) and IDAS, encoded by $M C I D A S)$. Geminin is a well-studied regulator of DNA replication that prevents re-replication through its cell cycle specific binding to CDT1, a factor required for origin licensing[25]. As its name reflects, Geminin acts as a dimer, homodimerizing through its central coiled-coil (CC) domain. Both 
GEMC1 and MCIDAS were identified due to the presence of a similar CC domain and all 3 proteins can homo or heterodimerize[26-29]. This feature appears to be functionally relevant, as the CC domains are required for some of their key functions in all cases, although the physiological significance of heterodimerization remains unclear[30,31].

Studies in zebrafish and mice identified GEMC1 as a critical upstream mediator of the MCC differentiation program that is activated upon Notch inhibition[30,32-34]. GEMC1 deficient mice lack MCCs in every tissue where they are normally present, leading to penetrant hydrocephalus and infertility. While MCCs are absent from the murine airway in GEMC1 deficient mice, no respiratory defects have been reported, potentially due to sterile housing conditions, although significant discrepancies remain regarding the lifespan of GEMC1 deficient mice derived in different colonies where they range from 9 days to over 2 years[30,32].

The induction of Gemcl and Mcidas in the developing murine brain is temporally distinct and MCIDAS deficient mice develop morphologically identifiable MCCs that express early transcription factors, including p73 and FOXJ1, but fail to amplify centrioles or generate cilia[33,35]. Air liquid interface (ALI) cultures from MCIDAS deficient mice showed no increase in the expression of genes implicated in centriole amplification, including $C C N O, C D C 20 B, C C D C 78$ or DEUP1, indicating that GEMC1 is not sufficient to activate these genes when under its normal physiological regulation[35]. Thus, a twostep process has been proposed; GEMC1 activates MCIDAS and other key transcription factors to promote MCC specification and MCIDAS subsequently activates the expression of genes required for multiciliogenesis[35]. The overexpression of MCIDAS can trigger MCC differentiation in frog skin and mouse cells (the latter in conjunction with an E2F4-activation domain fusion), indicating that MCIDAS is one of the most crucial targets of GEMC1[36,37]. Consistent with this, overexpression of GEMC1 in frog embryos or murine ALI cultures also generates supernumerary MCCs in a manner that requires MCIDAS in ALI cultures[34,35]. Curiously, the overexpression of human or zebrafish GEMC1 is not sufficient to generate supernumerary MCCs in zebrafish, potentially indicating that essential cofactors or important post-translational modifications of GEMC1 are limiting[34].

\section{Transcriptional activation by GEMC1 and MCIDAS}

As GEMC1 and MCIDAS lack clear DNA binding domains, it remained an open question as to how they could activate transcription. Work in frogs first showed that a C-terminal domain of MCIDAS, absent in Geminin, dubbed the TIRT domain due to a repetitive amino acid motif sequence, interacted with the E2F4 and E2F5 transcription factors heterodimerized with DP-1[38]. This connected the activity of MCIDAS to previous and subsequent work that established a key role for E2F4 and E2F5 in murine brain, airway and germline MCC development[38-41]. While it lacks the specific TIRT aminoacid repetition, the C-terminus of GEMC1 contains a homologous "TIRT" domain that is also required for E2F4/5-DP1 binding and transcriptional activity[30,32]. Recent evidence suggests that the TIRT 
domains of GEMC1 and MCIDAS are not functionally identical. In immunoprecipitation experiments, mouse and human GEMC1 showed a higher affinity for E2F5 than E2F4 and this specificity could be eliminated by replacing the TIRT domain of GEMC1 with that of MCIDAS[35]. Moreover, coexpressing E2F5, but not E2F4, with GEMC1 enhanced the activation of FOXJ1. In contrast, MCIDAS was shown to have similar affinity to both E2F4 and E2F5, potentially enabling more efficient activation of the genes necessary for centriole amplification[35]. One possibility that is consistent with current data is that GEMC1 displaces pocket protein inhibitors of E2F5, such as RB, p107 or p130, but does not strongly activate the MCC transcriptional program until it is reinforced by MCIDAS expression and its interactions with both E2F4 and E2F5. While more detailed biochemical and structural studies remain to be performed, the emerging picture is that GEMC1 and MCIDAS play sequential roles that utilize specific E2F4/5-DP1 interactions influenced by differences in their C-terminal domains.

While both E2F4 and E2F5 have been clearly linked to MCC generation, discerning their specific roles has been challenging in mice due to their essentiality and influence on the development of many tissues. E2F4 and E2F5 have been typically characterized as repressive E2Fs, in contrast to the activating E2Fs, E2F1-3, and bind to the regulatory regions of hundreds of genes to repress cell cycle genes during G0 and $\mathrm{G} 1$ in conjunction with the RB family proteins and interactions with the MuvB/DREAM complex[42]. Recent work in zebrafish showed that some tissue specificity exists with regards to their role in MCC generation, but that this reflects the relative expression levels of E2f4 or E2f5 in those tissues, rather than specific functions of either factor, consistent with work in frogs that suggested redundancy between E2F4 and E2F5[38,43]. Surprisingly, Mcidas was not required for MCC generation in the nasal placode of zebrafish, indicating that in some circumstances, GEMC1 is sufficient to promote centriole amplification through E2F4/5[43]. Whether this reflects inherent differences in target gene activation, increased expression of GEMC1 or the relative numbers of centrioles needed in MCCs in this tissue remains to be determined.

In overexpression experiments in frogs or human cells, Geminin acted as a potent inhibitor of transcriptional activation by GEMC1 and MCIDAS through CC-mediated interactions and the formation of a ternary complex with the E2F4 or E2F5-DP1 transcription factors[30,32,38]. It was proposed that Geminin may prevent the activation of the multiciliogenesis program until dividing cells exit the cell cycle, as the consequent centriole amplification would cause mitotic spindle defects[38]. Geminin was previously implicated in transcriptional regulation through interactions with the BRG1 component of the SWI/SNF complex, that is known to interact with E2F4/5, and controls the expression of a number of transcription factors[44-47]. Whether Geminin acts only by impairing GEMC1 or MCIDAS homodimerization and transcriptional activation through E2F4/5, or has a more complex role involving SWI/SNF or transcription factor interactions, has not been clearly established. 
Recent work using lineage tracing in the mouse ependyma demonstrated that in adult mice, the direct generation of MCCs from B1 astrocyte progenitors can occur[48]. This is reminiscent of previous studies showing that following damage to the airway, MCCs can be generated directly from p63+ basal cells[49]. In the ependyma, the rate of symmetric or asymmetric divisions can be influenced by the transient overexpression of either Geminin, that favors symmetric divisions and the B1 cell fate, or GEMC1 that promotes MCC differentiation[48]. While this suggests that the expression and stoichiometry of Geminin and GEMC1 is highly relevant to cell fate, it remains unclear if direct interactions between Geminin and GEMC1 play a role in E2F4/5-mediated MCC specification under physiological conditions.

\section{Other transcription factors required for MCC generation}

A crucial function of GEMC1 and MCIDAS is to activate numerous downstream transcription factors (TFs). This expanding list includes FOXJ1, FOXN4, RFX2, RFX3, MYB and P73, among others (Table S1). Each of these TFs has been demonstrated to play critical, and in some cases cooperative, roles in enabling the gene expression of numerous proteins involved in MCC differentiation.

The TF p73 (encoded by TP73 and Trp73 in humans or mice) is a member of the p53 family that also includes p63, a marker of basal progenitor cells that give rise to MCCs in the airway[15]. Given its relationship to $\mathrm{p} 53$, one of the most well studied tumor suppressors, $\mathrm{p} 73$ was extensively studied in mice and was shown to cause a number of developmental phenotypes, many of which have been recently linked to defects in MCC differentiation[50]. The TP73 gene generates 2 major isoform groups via 2 promoters; the activating (TAp73) or an N-terminally truncated (DNp73) form lacking the transactivating domain. Reduced numbers of MCCs were observed in the airway, oviducts and efferent ducts of mice lacking both isoforms, or only TAp73, and ChIP experiments linked p73 directly to genes involved in multiciliogenesis, such as FoxJ1, $R f x 2$, or $R f x 3$ [51,52]. P73 forms a ternary complex with GEMC1 and E2F5 that is stabilized by both the CC and TIRT domains of GEMC1, and this complex can activate the TP73 promoter[31,51,53]. P73 is induced by both GEMC1 and MCIDAS through their respective E2F4/5-DP1-containing complexes, although it remains unclear if MCIDAS also interacts with p73. P73 expression has been reported in p63+ basal cells and Radial Glial Cells (RGCs), that act as MCC progenitors in the airway and brain, respectively, suggesting an early role for p73 in MCC fate specification independent of GEMC1 or MCIDAS, although this remains controversial[50-52,54]. The requirement for $\mathrm{p} 73$ appears to also vary depending on the isoform, tissue and cell type. In contrast to the airway, where TAp73 deletion impaired MCC formation, these mice did not exhibit hydrocephalus or show impaired MCC formation in the brain due to compensation from the miR-449a-c cluster[20]. Combined deletion of TAp73 and miR-449a-c impaired MCC generation in the choroid plexus (CP) and deletion of both TP73 isoforms impaired MCC generation in ependymal cells[20,55]. Therefore, MCC 
fate may be subjected to tissue-specific feedback modulation, warranting further comparison of the transcriptional regulation and signaling pathways involved in different tissues.

FOXJ1 was the first transcription factor shown to be required for MCC differentiation and is frequently used as a marker of MCCs in all tissues[56-59]. FOXJ1 is now a well-established target of p73 and GEMC1, that likely work together to activate its expression at early stages of multiciliogenesis[30,32,35,51,52]. FOXJ1 is also regulated by MCIDAS, as the absence of MCIDAS activity strongly reduced FOXJ1 expression in frog skin and human airway cells, but airway MCCs in MCIDAS deficient mice were FOXJ1 positive[35,37,60]. FOXJ1 promotes MCC differentiation by regulating a cohort of genes involved in the production, assembly, transport, and docking of the inner and outer dynein arms, radial spokes and the central pair as well as genes that encode intraflagellar transport (IFT) proteins[56,61-65]. Studies in the human airway demonstrated that the RFX3 TF functions as a transcriptional coactivator of FOXJ1, helping to induce the expression of cilia genes involved in differentiation towards the MCC lineage[61]. Similarly, recent work demonstrated that FOXJ1 preferentially binds enhancers and is stabilized at promoters of cilia genes through cooperative interactions with the TF RFX2[66]. The stability of the MCC lineage is reportedly dependent on a constant FOXJ1 protein expression level in order to prevent cellular de-differentiation back into a gliallike morphology in mouse ependymal MCCs[67]. Recently, human patients with FOXJ1 mutations were shown to have defects in motile cilia, left right patterning defects and impaired basal body docking in MCCs[68].

Another Forkhead family transcription factor, FOXN4, was implicated in MCC generation in frog skin and identified as an early target of MCIDAS[69]. Similar to FOXJ1, the promoter binding of FOXN4 was enhanced by RFX2, and its depletion using morpholinos or CRISPR/CAS9 editing impaired multiciliogenesis to a similar extent as FOXJ1, although through effects on distinct target genes. Its role in MCCs in other organisms has yet to be explored.

An shRNA based screening strategy in cultured primary human basal cell ALI cultures identified TRRAP, a component of several histone acetyltransferase complexes, to be required for MCC generation[70]. Analysis of ALI cultures using immunofluorescence showed that TRRAP acted at an early time following NOTCH inhibition and accumulated in MCCs prior to FOXJ1. Moreover, it was required for MCIDAS expression, suggesting that it was necessary for GEMC1 activity, a possibility that remains to be formally tested. In addition to TRRAP, ATAD2B, a AAA domain containing ATPase, was also identified in the screen and validated in subsequent experiments[70]. While it was not pursued further, it contains a bromodomain, binds acetylated histones, is regulated by E2Fs and has been implicated in transcription in cancer, suggesting it may also play a transcriptional role in MCCs [71,72]. 
The Aryl hydrocarbon receptor (AHR), a ligand activated transcription factor that responds to a variety of xenobiotic chemicals or oxygen levels, has been linked to MCC generation through work in both mice and frogs[73,74]. In ALI cultures from Ahr- mice, the expression of Mcidas, Ccno and Cdc20b were all strongly impaired, suggesting that AHR may function in conjunction with GEMC1 to activate Mcidas, and potentially facilitate the ability of MCIDAS to activate $C c n o$, that was identified as a direct AHR target[74]. In both murine ALI cultures and depletion experiments in frog skin, MCC numbers were reduced and many of the FOXJ1 positive cells showed disorganized ciliary patterns. At late embryonic stages, AHR deficient mice showed reduced numbers of airway MCCs in vivo but adult mice did not exhibit the same defects, indicating that redundant pathways may provide compensation for AHR loss at later developmental stages. Whether AHR plays a role in MCC generation in other tissues, such as the brain or germline, remains unclear, but hydrocephalus, that usually accompanies loss of ependymal MCCs, was not reported, and although AHR loss has been linked to reduced fertility in aging male mice, available evidence does not suggest that this is due to defects in the MCCs of the efferent ducts[75].

Additional regulators of MCC transcription and differentiation, including IL-6, STAT3, FANK1 and JAZF1 have been identified using in vivo and in vitro models[76,77] and there is little doubt that many additional transcriptional regulators will be involved in this complex differentiation program. Future work will be needed to further deconvolve their functions, regulation and target genes, as well as their tissue specific roles.

\section{Centrioles, cell cycle regulators and the deuterosome}

In proliferating cells, canonical centriole duplication is highly restricted to a single round per cell cycle to avoid mitotic defects that can result from multipolar spindle formation. This canonical motherdaughter (MD) pathway is tightly regulated and has been well described to involve the interplay of PLK4, CEP63, CEP152, and SAS6, among other factors[78]. The mother and daughter centrioles inherited by the cell following mitosis serve as templates for pro-centriole generation that gives rise to 2 new daughter centrioles in a process coordinated with cell cycle progression. Aside from contributing to the formation of the microtubule-organizing center (MTOC) of the mitotic spindle, the mother centriole contains distal appendages that facilitate docking to become a BB that can act as a base for the extension of a primary cilium that functions to integrate a diverse range of environmental signals[79]. A defining characteristic of post-mitotic MCCs is the massive amplification of centrioles to form the BBs needed for generating multiple motile cilia. The MD pathway of centriole duplication is estimated to account for only around $10 \%$ of $\mathrm{BB}$ production in MCCs[80]. The bulk of centriole production in MCCs is normally accomplished by the deuterosome-dependent (DD) pathway, that uses a ring-shaped, electron dense structure called the deuterosome to facilitate centriole expansion[1,81,82]. Many deuterosomes can form during multcilliogenesis, each nucleating multiple procentrioles, thereby 
evading the restrictions that regulate the MD centriole duplication pathway to allow rapid $\mathrm{BB}$ production.

While the deuterosome was first described many decades ago only recently has its major structural component, DEUP1, been identified[81,83]. DEUP1 evolved through a duplication of CEP63, that plays a key role in centriole duplication in the MD pathway. In addition to DEUP1, CCDC78 that localizes to the acentriolar sites of centriole biogenesis and CDC20B that localizes to the perideuterosomal region are the only other deuterosome specific proteins identified in both mouse and frog MCCs[82,84]. Other components of the deuterosome are common to the MD pathway, including Pericentrin (PCNT), $\gamma$-tubulin, and CEP152, that are all located on the peripheral ring[6]. However, there are likely additional proteins that comprise the center core or outer wall of the deuterosome that remain to be identified.

Until recently, the prevailing view was that deuterosome synthesis occurred de novo and did not require centrosomal centrioles. Detailed live imaging of newly synthesized centrioles during cultured brain MCC differentiation showed that deuterosomes were seeded by the daughter centrosomal centriole[80]. However, in the last year, a handful of studies showed that deuterosomes with multiple centrioles could be produced when both parent centrioles were depleted[85-87]. Deuterosomes were able to spontaneously synthesize from the pericenteriolar material (PCM) in a manner that did not require PLK4, in contrast to earlier reports[81]. This opens up a possibility that deuterosomes are created in the PCM, and then only briefly associate with the daughter centrioles to facilitate the loading of procentrioles that occur there[87]. Recent work has implicated cytoplasmic E2F4 in the initiation of centriole amplification[88]. A cytoplasmic pool of E2F4 was shown to co-localize with various components of centriole amplification, including PCM1, and it was proposed that this forms the core of the fibrous granules that have been observed overlapping with or adjacent to deuterosomes. It will be important in future work to fully elucidate the composition of the PCM in MCCs and explore potential species-specific differences.

The ordered stages of the deuterosome cycle have come in to clearer view through the use of mouse models and advancements in cell culture systems and super-resolution microscopy techniques over the last few years. At the onset of centriole amplification, a Centrin-2 cloud or 'halo' accumulates around the pre-existing centrosome (Stage-I or Amplification (A)) and this signal intensifies to adopt a 'flowerlike' shape (Stage-II or Growth $(\mathrm{G})$ ), corresponding to maturing centrioles that appear in a synchronized manner. And finally, the coordinated disengagement (Stage III or D) and release of centrioles and their migration to the apical surface as BBs takes place[80].

Strikingly, the deuterosome cycle appears to rely on much of the same cell cycle machinery that plays a role during stepwise MD centriole duplication in proliferating cells, although the precise regulatory 
details remain unclear. Following cell cycle exit, radial glial progenitors re-express cell cycle markers, including KI67, CDK1, CDK2 and phosphorylated histone H3-Serine10, without performing DNA synthesis or undergoing mitotic division[89]. Through the use of a number of small molecule inhibitors or agonists, key roles in the regulation of the deuterosome cycle were demonstrated for CDK1, CDK2, PLK1, APC/C and CDC20[7,89,90]. This repurposing of the mitotic oscillator also appears to require the poorly understood $\mathrm{CDC} 20 \mathrm{~B}$, as well as $\mathrm{CCNO}$, that has its highest expression levels during the earliest phase of deuterosome formation[84,91,92]. CCNO mutant mice exhibit large, malformed deuterosomes and produce fewer $\mathrm{BBs}$, suggesting that $\mathrm{CCNO}$ was required for deuterosome stability[91]. MCCs generated in ALI cultures derived from CCNO knockout mice also display significant transcriptional dysregulation, suggesting that $\mathrm{CCNO}$ functions to restrain the activation of key MCC genes, including MCIDAS[91]. This role of CCNO could prevent the overproduction of deuterosome components and contribute to the observed structural abnormalities. Repurposing the existing cell cycle regulation machinery appears to provide an elegant solution to regulating centriole amplification in the context of MCCs. Future work will be needed to understand its regulation and the specific roles of factors such as CDC20B and CCNO that are expressed primarily in MCCs.

Recently, surprising work has questioned the necessity of the deuterosome for centriole amplification in MCCs. In mouse tracheal MCCs in vitro, depletion of DEUP1 caused a reduction in centriole amplification and CEP63 depletion did not influence centriole numbers in MCCs, due to apparent compensation from DEUP1[81]. Depletion of CEP63 in vivo, that reduces MD pathway centriole duplication in neural progenitor cells, also did not have an impact on centriole numbers in MCCs[93,94]. However, the deletion of DEUP1 in vivo revealed that mice were able to generate MCCs normally in the absence of deuterosomes, indicating they are dispensable for procentriole amplification during multiciliogenesis in mice and frogs[94]. Concomitant depletion of CEP63, to impair the MD pathway, led to a slight reduction in centriole amplification in vitro, indicating that there is likely minimal compensation from the MD pathway in the absence of DEUP1[94]. This finding remains to be extended to MCCs in all tissues but it opens up the field to a number of exciting possibilities. They speculate that centriole synthesis occurs within a cloud of fibrogranular material and PCM, and that deuterosomes function to relieve the parental centrioles of the high numbers of procentrioles that form along their length. Supporting this possibility, flatworms and some species of ray-finned fish (such as zebrafish) are capable of producing MCCs and do not encode DEUP1 or generate deuterosomes[9597]. This establishes that another route for de novo procentriole generation in MCCs can function independently of both the MD and DD pathways and provide compensation for their loss. It was proposed that this pathway may be equivalent to pericentriolar satellites that occur in non-MCCs given that they are scaffolded by PCM1 that is enriched in fibrogranular material[94,98].

\section{Late transcriptional roles, polarization and cilia assembly}


Like many other types of epithelial cells, MCCs are polarized and aligned by the planar cell polarity (PCP) pathway[99]. Additionally, MCCs in both the frog skin and mammalian airway originate in a basal epithelial layer and migrate apically, through a process known as radial intercalation[100,101]. PCP and radial intercalation are both coordinated with ciliogenesis in MCCs through the actions of many proteins, including, dystroglycan, Rab11, the Par complex, RFX2, Slit2, Septins and RhoA[102106]. Among these, the transcription factor RFX2 was identified as a central regulator of PCP, radial intercalation and ciliogenesis in frogs and other vertebrates[105,107,108]. Recent analysis of mice lacking RFX2 identified a key role in the regulation of cilia related genes during spermiogenesis, but suggested that it is dispensable for MCC generation in higher mammals, as hydrocephalus and respiratory defects were not reported[109-111]. So while RFX2 is expressed in cells with motile cilia in mice, further analysis of tissues that contain MCCs will be needed to establish its roles in higher mammals and determine if RFX3 or other factors may compensate for its loss[108-111].

How MCCs control the number of centrioles/BBs and cilia generated remains unclear. Studies using frog larvae showed that during radial intercalation, a network of apical and subapical actin forms in a lattice connecting the centrioles, and generates a 2D force that expands the apical surface of MCCs to accommodate the required number of BBs and ensure the even distribution of cilia[100,112]. Recent work demonstrated that centriole numbers remain normal in mouse cells lacking DEUP1 and a striking correlation between cell surface area and centriole number in MCCs was reported[85,94]. Manipulation of cell surface area in mouse tracheal epithelial cells, using differences in collagen density, showed that centriole numbers were impacted accordingly[85]. This suggests that either cell surface area, or potentially cortical stiffness, dictates the number of centrioles generated via early stage transcriptional mechanisms, and suggests potential links to the cytoskeletal rearrangements that occur during PCP and radial intercalation.

The YAP transcription factor, a central component of the Hippo signaling pathway, responds to cell surface tension and mechanical forces, regulates epithelial size during airway development and has been linked to both actin cytoskeletal rearrangements and ciliogenesis[113,114]. YAP is expressed in mouse airway MCCs, several YAP interactors have been localized to BBs, and in frogs, YAP nuclear translocation and increased tissue stiffness occur during regeneration of the multiciliated epithelium[115,116]. However, YAP is not required for MCC generation per se and it remains unclear if YAP plays an important role in dictating MCC size or centriole numbers[117].

Following their amplification, centrioles are transported to the apical surface in an actin-myosin dependent manner and the organization and attachment of the BBs takes place, regulated in part by ERK7, DVL1/2, CapZIP, CELSR2/3, WDR5, GTPases and the miR-34/449 family to ensure correct cilia function and integrity of the epithelium [19,37,50,99,118-126]. While the details of transcriptional crosstalk with the cytoskeleton and PCP pathways remains to be fully elucidated, MYB, FOXJ1, p73 
RFX2 and RFX3, all contribute to the regulation of genes that ensure correct BB migration and docking, axoneme outgrowth, and motility, as well as cilia beating in frogs and mice[61,65,66,105,123,127129].

\section{Consequences of MCC dysfunction}

While present only in a few tissues, defective MCCs contribute to congenital disorders, such as primary ciliary dyskinesia (PCD) and Reduced generation of multiple motile cilia (RGMC), the latter due to defects specifically in MCCs[60,130,131]. Thus far, mutations in 2 genes have been implicated in RGMC: $M C I D A S$ and $C C N O$. Both genes are located adjacent to each other on Chromosome 5 (5q11.2) that also contains $C D C 20 B$ that encodes both a protein and the Mir449a/b/c genes. RGMC patients present clinically with hydrocephalus, recurrent airway infections and bronchiectasis. Due to the ages of the patients, little data regarding fertility has been reported, although some female patients have presented with infertility[60,130,131]. While RGMC represents an extreme case, it is possible that less severe mutations or tissue specific defects in the function or expression of key MCC factors may result in more subtle pathologies, such as subfertility, scoliosis or normal pressure hydrocephalus[132,133]. Consistent with this possibility, a mutation in GEMCl was recently identified in a patient with congenital hydrocephalus but respiratory defects or fertility issues were not reported[134]. MCIDAS mutations that have been identified in RGMC are located in the TIRT domain of MCIDAS and interfere with binding of the E2F4/5 transcription factors, highlighting again the central importance of MCIDAS in the MCC transcriptional pathway[60]. A new report identified the NEK10 kinase in familial bronchiectasis and demonstrated its expression in airway MCCs[135]. While these patients exhibited respiratory distress, similar to that observed in RGMC, they generated airway MCCs with subtle morphological defects and shorter cilia that were incapable of mucociliary clearance. Proteomic analysis of NEK10 deficient MCCs revealed widespread effects on the phosphorylation of many proteins required for motile cilia function, indicating that NEK10 may be a key regulator of many aspects of MCC function.

\section{Conclusions and open questions}

Rapid advances have been made in determining the molecular events that control MCC generation in multiple tissues. However, many open questions remain unresolved. The structural and functional similarity of GEMC1 and MCIDAS raises the question as to whether they play distinct or redundant roles in transcription. The sequential nature of their activation, their antagonism with Geminin and their distinct contributions to MCC differentiation have been well documented[25,26,28,30,32,33,35,38,48]. Whether this reflects differential regulation of their activities, post-translational regulation of their stoichiometry or distinct functional domains that have yet to be identified remains unknown. Geminin levels are well established to be regulated by the Ubiquitin proteasome system, exemplified by the use of its N-terminal D-box degron in the Fucci system to monitor cell cycle[136]. MCIDAS also appears 
to have a functional D-box motif and is degraded during anaphase in cancer cells but whether this is relevant to its activity in post-mitotic MCCs has not been established[27]. The 3'UTR of GEMC1 contains overlapping Mir449 and CPE sites, required for binding of CPEB translational regulators, that may function to tightly control mRNA and protein levels in response to regulatory cues[30]. Tissues from mice lacking CCNO have been reported to exhibit high levels of Mcidas expression, suggesting that modulation of CDK activity, that is clearly important for the centriole amplification process, may also play a direct role in regulating transcriptional feedback via GEMC1 and MCIDAS but this remains to be formally demonstrated[89,91]. MCCs in many tissues, particularly in the airway, must be periodically replaced due to damage to the epithelium. The maintenance of mRNA levels of GEMC1 and other transcriptional activators may serve to prime the rapid replenishment of cilia in existing MCCs following damage, and whether GEMC1 is required for the direct generation of MCCs from progenitor cells in this context also remains to be tested[48,49].

A common feature reported for both GEMC1 and CCNO deficient mice that remains unexplained was growth defects[30,32,92]. We speculated that this could be secondary to fluid pressure on the developing brain that could influence pituitary gland function, although we could not detect alterations in its function. Alternatively, it could reflect functions unrelated to MCC generation, for example in the regulation of DNA replication at early developmental stages. Mutations in Geminin are associated with Meier-Gorlin syndrome that is characterized by primordial dwarfism[137]. While the expression of GEMC1 and MCIDAS appears to be restricted to MCCs, CCNO expression is detected in other tissues, including the pituitary and thyroid glands, and may have distinct functions. Future work using conditional mouse models can begin to address these possibilities.

Aberrant expression of key MCC specific genes can also be observed in many cancers and some evidence suggests they may play functional roles[138-140]. The aberrant expression or depletion of GEMC1 and MCIDAS in cancer cell lines has been shown to impact DNA replication and could potentially activate transcription factors such as E2F4, p73 and FOXJ1 that have been implicated in cancer development, and could provoke centriole amplification and mitotic defects[26-28]. The potential of $\mathrm{CCNO}$ and $\mathrm{CDC} 20 \mathrm{~B}$ to impact cell cycle regulation or apoptosis is also potentially relevant to their expression in human cancers[138,141].

The intriguing observations that MCCs coordinate cell area with centriole numbers and can perform this function in the absence of deuterosomes by repurposing cell cycle machinery opens up a number of new mechanistic questions to be addressed[85,89,94]. And finally, microarrays, RNAseq and more recently, single cell sequencing, of multiciliated cells has identified new genes in their transcriptional programs that have yet to be functionally characterized[30,38,66,69,142-144]. The careful comparisons between in vitro systems and MCCs in distinct tissues and organisms will no doubt also reveal new 
aspects of their diversity and specialized functions that are important for human development and health.

\section{Acknowledgements}

The authors thank members of the Stracker lab, S.Roy, H.Zhao, M.Mahjoub, V.Costanzo, A.Holland, M.Lize and N.Spassky for ideas and fruitful discussions. We apologize to colleagues whose work could not be directly referenced due to space constraints. T.H.S. was funded by the Spanish Ministry of Science, Innovation and Universities (MCIU: PGC2018-095616-B-I00/GINDATA and FEDER), the Centres of Excellence Severo Ochoa award and the CERCA Programme. M.L. was funded by an FPI fellowship (MCIU).

\section{Author contributions}

M.L. and T.H.S. co-wrote and edited the manuscript.

\section{Declaration of Interests}

The authors declare no competing interests.

\section{Figure}




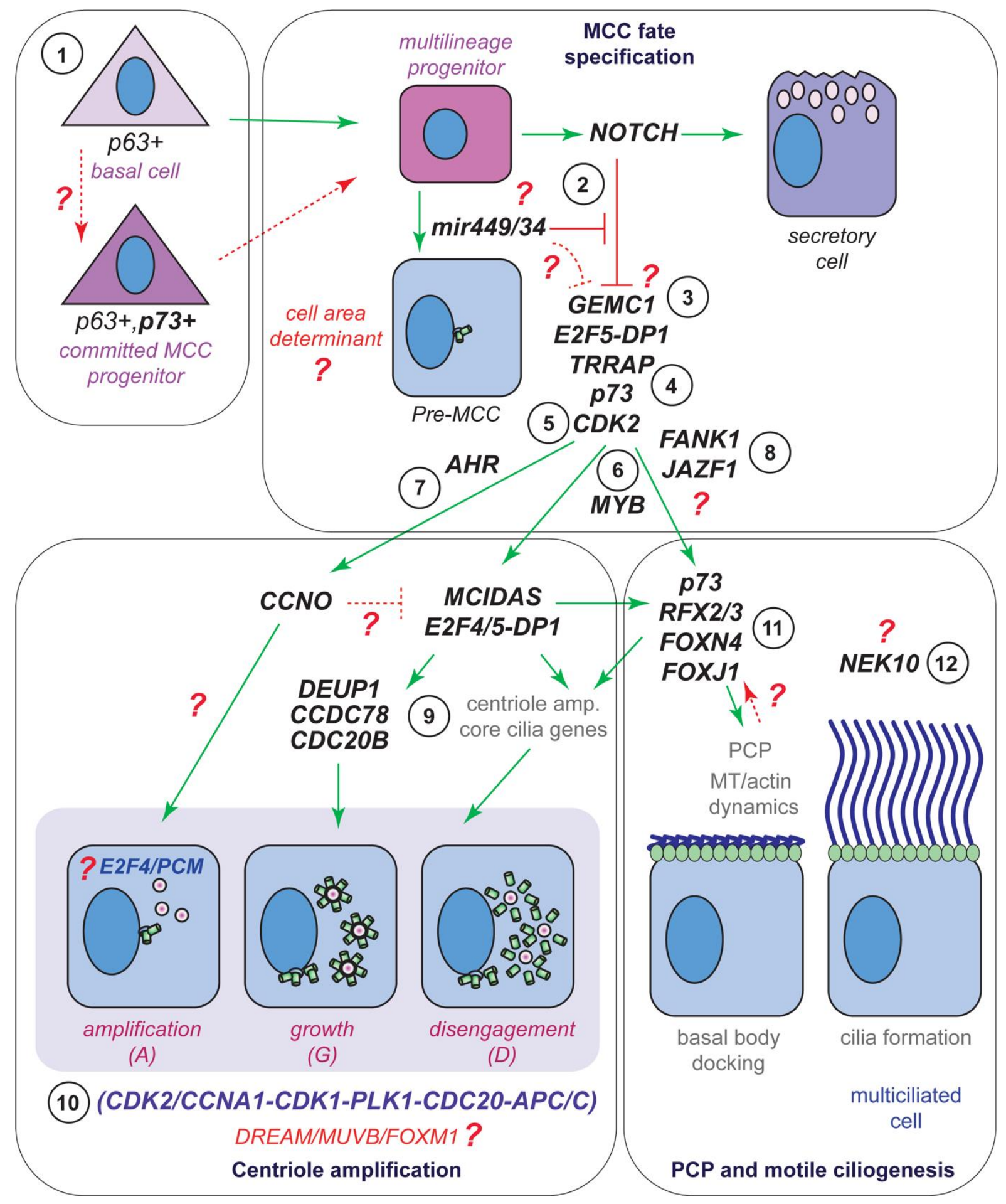

Figure 1: Knowns and unknowns of MCC transcription. The mammalian airway (trachea) is a well studied epithelial layer containing MCCs. Basal cells, that generate all other cell types of the trachea are p63 positive (+). 1) Induction of p73 at an early stage was proposed to mark p63+p73+ basal cells for an MCC fate, (?) although the regulation of this step remains unknown. 2) Inhibition of NOTCH instructs MCC fate and the activation of the mir-34/449 family was implicated in this step, (?) but how their induction is regulated remains an open question. (?) GEMC1 contains a mir-34/449 consensus site in its 3'UTR that may limit its expression levels. 3) (?) NOTCH inhibition activates GEMC1 through 
an unknown mechanism. GEMC1 interacts with E2F5-DP1 through its C-terminal domain, to activate the MCC differentiation program. 4) The transcriptional co-activator TRRAP and p73 act at an early step, prior to the induction of MCIDAS and p73 has been shown to interact with GEMC1. 5) CDK2 activity was demonstrated to play an early but thus far uncharacterized role in transcriptional activation. 6) MCIDAS induction required MYB, that also acts upstream of FOXJ1.7) During embryogenesis, but not in adults, AHR is required for GEMC1-mediated induction of CCNO. 8) Both GEMC1 and MCIDAS activate additional TFs, including FOXJ1, FOXN4, RFX2, RFX3 and p73 in a manner that requires FANK1 and JAZF1, (?) that remain to be functionally characterized in more detail. (?) Cell area correlates with centriole/cilia number and appears to be specified prior to centriole amplification through unknown mechanisms. 9) MCIDAS and multiple TFs activate genes required for deuterosomemediated centriole amplification and ciliogenesis. (?) CCNO mutants showed elevated levels of MCIDAS expression, suggesting a negative feedback role, but the mechanism of this has yet to be determined. (?) E2F4 promotes initiation of centriole duplication through a cytoplasmic role that remains to be fully elucidated. 10) The deuterosome cycle is regulated at distinct steps, in part by the canonical cell cycle machinery, as well as specialized factors including CCNA1, CCNO and CDC20B. (?) Whether the DREAM/MUVB-FOXM1 proteins regulate expression of the canonical or MCCspecific factors in a manner similar to a normal cell cycle remains unknown. 10) CCNO interacts with CDK1 and CDK2 and is required for normal deuterosome formation, (?) but its precise role remains unclear. (?) Similarly, the function of CDC20B in the deuterosome cycle remains unclear but appears to be independent of APC/C regulation. 11) MYB, FOXJ1, FOXN4, RFX2/3 and p73 all influence the expression of genes involved in PCP, cytoskeletal dynamics, basal body docking and cilia formation. (?) The molecular crosstalk between these processes and transcription remains unclear. 12) NEK10 was implicated in cilia length control and function through the phosphorylation of numerous proteins, (?) the molecular impact of which remains unknown. See main text for more detailed description and references. (?) Denotes open questions indicated in the figure.

\section{Supplementary Table S1:}

\begin{tabular}{|l|l|l|l|l|l|}
\hline Gene & Organism & Function & Domains & References \\
\hline$\underline{\text { AHR }}$ & X, M & $\begin{array}{l}\text { Upstream ligand- } \\
\text { activated transcription } \\
\text { factor that promotes } \\
\text { airway } \\
\text { differentiation }\end{array}$ & $\begin{array}{l}\text { A basic helix-loop- } \\
\text { helix (bHLH), DNA } \\
\text { binding, Per-Arnt- } \\
\text { Sim (PAS) 1\&2 }\end{array}$ & \\
\hline$\underline{\text { CCNO }}$ & M, H & $\begin{array}{l}\text { Suppresses MCIDAS } \\
\text { expression levels and } \\
\text { influences deuterosome }\end{array}$ & Cyclin domain & {$[91,130,131]$} \\
\hline
\end{tabular}




\begin{tabular}{|c|c|c|c|c|}
\hline & & $\begin{array}{l}\text { stability. Mutated in } \\
\text { RGMC patients. }\end{array}$ & & \\
\hline DP1 & $\mathrm{X}, \mathrm{M}$ & $\begin{array}{l}\text { Heterodimerizes with } \\
\text { E2F4 or E2F5 to regulate } \\
\text { transcription. Interacts } \\
\text { with GEMC1 and MCIDAS. }\end{array}$ & $\begin{array}{l}\text { Coiled-coil and } \\
\text { marked box (CM); } \\
\text { sequence specific } \\
\text { DNA-binding }\end{array}$ & {$[36,38,39,41,43,88]$} \\
\hline $\begin{array}{l}\text { E2F4 } \\
\text { E2F5 }\end{array}$ & $\mathrm{X}, \mathrm{D}, \mathrm{M}$ & $\begin{array}{l}\text { Heterodimerizes with DP1 } \\
\text { to regulate transcription. } \\
\text { Interacts with GEMC1 and } \\
\text { MCIDAS. }\end{array}$ & $\begin{array}{l}\text { Coiled-coil and } \\
\text { marked box (CM); } \\
\text { sequence specific } \\
\text { DNA-binding; } \\
\text { transactivation }\end{array}$ & {$[36,38,39,41,43,88]$} \\
\hline FANK1 & $M$ & $\begin{array}{l}\text { Promotes MCC } \\
\text { differentiation upstream } \\
\text { of FOXJ1 in vitro. }\end{array}$ & $\begin{array}{l}\text { Fibronectin type III; } \\
6 \text { Ankyrin repeat } \\
\text { domains }\end{array}$ & [76] \\
\hline FOXJ1 & $\mathrm{X}, \mathrm{D}, \mathrm{M}, \mathrm{H}$ & $\begin{array}{l}\text { Activates genes involved } \\
\text { in ciliogenesis, basal body } \\
\text { trafficking, BB docking at } \\
\text { the apical membrane and } \\
\text { axoneme growth. }\end{array}$ & Fork-head domain & $\begin{array}{l}{[56-} \\
59,64,65,68,120]\end{array}$ \\
\hline FOXN4 & $x$ & $\begin{array}{l}\text { Binds to many of the same } \\
\text { promoters as FOXJ1 and } \\
\text { complements its activity. }\end{array}$ & Fork-head domain & [69] \\
\hline GEMC1 & $\mathrm{X}, \mathrm{D}, \mathrm{M}$ & $\begin{array}{l}\text { Upstream transcriptional } \\
\text { activator, critical for MCC } \\
\text { specification. }\end{array}$ & $\begin{array}{l}\text { Geminin coiled coil } \\
\text { (CC); TIRT domain } \\
\text { (E2F/DP1 } \\
\text { interaction) }\end{array}$ & {$[30-33,53]$} \\
\hline JAZF1 & $M$ & $\begin{array}{l}\text { Promotes MCC } \\
\text { differentiation upstream } \\
\text { of FOXJ1 in vitro. }\end{array}$ & $\begin{array}{l}2 \times \mathrm{C} 2 \mathrm{H} 2 \text {-type zinc- } \\
\text { finger }(\mathrm{ZF}) ; 1 \quad 1 \quad \mathrm{x} \\
\mathrm{C} 2 \mathrm{H} 2-\text { degenerate } \\
\text { (ZF) }\end{array}$ & [76] \\
\hline MCIDAS & $\mathrm{X}, \mathrm{D}, \mathrm{M}, \mathrm{H}$ & $\begin{array}{l}\text { Downstream of GEMC1 a } \\
\text { crucial activator of key } \\
\text { transcription factors and } \\
\text { genes required for } \\
\text { centriole biogenesis }\end{array}$ & $\begin{array}{l}\text { Geminin coiled coil } \\
\text { (CC); TIRT domain } \\
\text { (E2F/DP1 } \\
\text { interaction) }\end{array}$ & {$[33,35,37,38,53,60]$} \\
\hline $\begin{array}{l}\text { MIR34/ } \\
\text { 449a-c }\end{array}$ & $\mathrm{X}, \mathrm{D}, \mathrm{M}$ & $\begin{array}{l}\text { Negatively regulate genes } \\
\text { in the MCC program. } \\
\text { Inhibit NOTCH signaling } \\
\text { by targeting ligands. }\end{array}$ & & {$[2,13,19-23]$} \\
\hline MYB & $\mathrm{M}, \mathrm{H}$ & $\begin{array}{l}\text { Early transcription factor } \\
\text { that can induce FOXJ1 }\end{array}$ & $\begin{array}{l}\mathrm{H}-\mathrm{T}-\mathrm{H} \text { motif } \mathrm{DNA} \\
\text { binding } 1,2 \text { \& } 3 \text {; } \\
\text { transactivation } \\
\text { domain }\end{array}$ & {$[127,129]$} \\
\hline P73 & $\mathrm{M}, \mathrm{H}$ & $\begin{array}{l}\text { Induced by GEMC1 and } \\
\text { MCIDAS, interacts with } \\
\text { GEMC1, directly regulates } \\
\text { a large number of genes } \\
\text { required for MCCs }\end{array}$ & $\begin{array}{l}\text { DNA binding; } \\
\text { transactivation } \\
\text { domain }\end{array}$ & {$[20,51,52,123]$} \\
\hline
\end{tabular}




\begin{tabular}{|c|c|c|c|c|}
\hline RFX2 & $X, D$ & $\begin{array}{l}\text { Stabilizes FOXJ1 at } \\
\text { promoters to activate cilia } \\
\text { genes. May recruit distal } \\
\text { enhancers to promoters. }\end{array}$ & $\begin{array}{l}\text { RFX-type winged- } \\
\text { helix DNA-binding }\end{array}$ & {$[18,66,105,107]$} \\
\hline RFX3 & $\mathrm{M}, \mathrm{H}$ & $\begin{array}{l}\text { Downstream of GEMC1, } \\
\text { modulates FOXJ1 to } \\
\text { activate genes required } \\
\text { for ciliogenesis and } \\
\text { motility. }\end{array}$ & $\begin{array}{l}\text { RFX-type winged- } \\
\text { helix DNA-binding }\end{array}$ & {$[61,128]$} \\
\hline TRRAP & $\mathrm{H}$ & $\begin{array}{lr}\text { Component of several } \\
\text { histone acetyltransferase } \\
\text { complexes. Acts } \\
\text { downstream of NOTCH } \\
\text { and upstream of MCIDAS. }\end{array}$ & $\begin{array}{l}\text { FRAP, } \\
\text { TRRA } \text { (FAT) and } \\
\text { FAT } \quad \text { C-terminal } \\
\text { (FATC) domain; } \\
\text { PI3K/PI4K domain }\end{array}$ & [70] \\
\hline
\end{tabular}

Table S1: Transcriptional regulators implicated in MCC differentiation are hyperlinked to uniport.org for domain information. Species are abbreviated: Xenopus laevis (X, frogs), Danio Rerio (D, zebrafish), Mus musculus ( $\mathrm{M}$, mice), Homo sapiens ( $\mathrm{H}$, humans).

\section{References}

[1] Spassky N, Meunier A. The development and functions of multiciliated epithelia. Nat Rev Mol Cell Biol 2017;18:423-36. doi:10.1038/nrm.2017.21.

[2] Yuan S, Liu Y, Peng H, Tang C, Hennig GW, Wang Z, et al. Motile cilia of the male reproductive system require miR-34/miR-449 for development and function to generate luminal turbulence. Proc Natl Acad Sci USA 2019;116:3584-93. doi:10.1073/pnas.1817018116.

[3] Yan X, Zhao H, Zhu X. Production of Basal Bodies in bulk for dense multicilia formation. [version 1; peer review: 2 approved]. F1000Res 2016;5. doi:10.12688/f1000research.8469.1.

[4] Patmanidi AL, Champeris Tsaniras S, Karamitros D, Kyrousi C, Lygerou Z, Taraviras S. Concise Review: Geminin-A Tale of Two Tails: DNA Replication and Transcriptional/Epigenetic Regulation in Stem Cells. Stem Cells 2017;35:299-310. doi:10.1002/stem.2529.

[5] Kyrousi C, Lygerou Z, Taraviras S. How a radial glial cell decides to become a multiciliated ependymal cell. Glia 2017;65:1032-42. doi:10.1002/glia.23118.

[6] Boutin C, Kodjabachian L. Biology of multiciliated cells. Curr Opin Genet Dev 2019;56:1-7. doi:10.1016/j.gde.2019.04.006.

[7] Al Jord A, Spassky N, Meunier A. Motile ciliogenesis and the mitotic prism. Biol Cell 2019. doi:10.1111/boc.201800072.

[8] Krasinska L, Fisher D. Non-Cell Cycle Functions of the CDK Network in Ciliogenesis: Recycling the Cell Cycle Oscillator. Bioessays 2018;40:e1800016. doi:10.1002/bies.201800016. 
[9] Nemajerova A, Amelio I, Gebel J, Dötsch V, Melino G, Moll UM. Non-oncogenic roles of TAp73: from multiciliogenesis to metabolism. Cell Death Differ 2018;25:144-53. doi:10.1038/cdd.2017.178.

[10] Meunier A, Azimzadeh J. Multiciliated cells in animals. Cold Spring Harb Perspect Biol 2016;8. doi:10.1101/cshperspect.a028233.

[11] Marcet B, Chevalier B, Luxardi G, Coraux C, Zaragosi L-E, Cibois M, et al. Control of vertebrate multiciliogenesis by miR-449 through direct repression of the Delta/Notch pathway. Nat Cell Biol 2011;13:693-9. doi:10.1038/ncb2241.

[12] Kessler M, Hoffmann K, Brinkmann V, Thieck O, Jackisch S, Toelle B, et al. The Notch and Wnt pathways regulate stemness and differentiation in human fallopian tube organoids. Nat Commun 2015;6:8989. doi:10.1038/ncomms9989.

[13] Marcet B, Chevalier B, Coraux C, Kodjabachian L, Barbry P. MicroRNA-based silencing of Delta/Notch signaling promotes multiple cilia formation. Cell Cycle 2011;10:2858-64. doi:10.4161/cc.10.17.17011.

[14] Tsao P-N, Vasconcelos M, Izvolsky KI, Qian J, Lu J, Cardoso WV. Notch signaling controls the balance of ciliated and secretory cell fates in developing airways. Development 2009;136:2297-307. doi:10.1242/dev.034884.

[15] Pardo-Saganta A, Tata PR, Law BM, Saez B, Chow RD-W, Prabhu M, et al. Parent stem cells can serve as niches for their daughter cells. Nature 2015;523:597-601. doi:10.1038/nature14553.

[16] Guseh JS, Bores SA, Stanger BZ, Zhou Q, Anderson WJ, Melton DA, et al. Notch signaling promotes airway mucous metaplasia and inhibits alveolar development. Development 2009;136:1751-9. doi:10.1242/dev.029249.

[17] Ma M, Jiang Y-J. Jagged2a-notch signaling mediates cell fate choice in the zebrafish pronephric duct. PLoS Genet 2007;3:e18. doi:10.1371/journal.pgen.0030018.

[18] Liu Y, Pathak N, Kramer-Zucker A, Drummond IA. Notch signaling controls the differentiation of transporting epithelia and multiciliated cells in the zebrafish pronephros. Development 2007;134:1111-22. doi:10.1242/dev.02806.

[19] Chevalier B, Adamiok A, Mercey O, Revinski DR, Zaragosi L-E, Pasini A, et al. miR-34/449 control apical actin network formation during multiciliogenesis through small GTPase pathways. Nat Commun 2015;6:8386. doi:10.1038/ncomms9386.

[20] Wildung M, Esser TU, Grausam KB, Wiedwald C, Volceanov-Hahn L, Riedel D, et al. Transcription factor TAp73 and microRNA-449 complement each other to support multiciliogenesis. Cell Death Differ 2019. doi:10.1038/s41418-019-0332-7.

[21] Song R, Walentek P, Sponer N, Klimke A, Lee JS, Dixon G, et al. miR-34/449 miRNAs are required for motile ciliogenesis by repressing cp110. Nature 2014;510:115-20. doi:10.1038/nature13413.

[22] Lizé M, Herr C, Klimke A, Bals R, Dobbelstein M. MicroRNA-449a levels increase by several orders of magnitude during mucociliary differentiation of airway epithelia. Cell Cycle 2010;9:4579-83. doi:10.4161/cc.9.22.13870.

[23] Wang L, Fu C, Fan H, Du T, Dong M, Chen Y, et al. miR-34b regulates multiciliogenesis during organ formation in zebrafish. Development 2013;140:2755-64. 
doi:10.1242/dev.092825.

[24] Kiyokawa H, Morimoto M. Notch signaling in the mammalian respiratory system, specifically the trachea and lungs, in development, homeostasis, regeneration, and disease. Dev Growth Differ 2019. doi:10.1111/dgd.12628.

[25] Arbi M, Pefani D-E, Taraviras S, Lygerou Z. Controlling centriole numbers: Geminin family members as master regulators of centriole amplification and multiciliogenesis. Chromosoma 2018;127:151-74. doi:10.1007/s00412-017-0652-7.

[26] Balestrini A, Cosentino C, Errico A, Garner E, Costanzo V. GEMC1 is a TopBP1-interacting protein required for chromosomal DNA replication. Nat Cell Biol 2010;12:484-91. doi:10.1038/ncb2050.

[27] Pefani D-E, Dimaki M, Spella M, Karantzelis N, Mitsiki E, Kyrousi C, et al. Idas, a novel phylogenetically conserved geminin-related protein, binds to geminin and is required for cell cycle progression. J Biol Chem 2011;286:23234-46. doi:10.1074/jbc.M110.207688.

[28] Caillat C, Pefani D-E, Gillespie PJ, Taraviras S, Blow JJ, Lygerou Z, et al. The Geminin and Idas coiled coils preferentially form a heterodimer that inhibits Geminin function in DNA replication licensing. J Biol Chem 2013;288:31624-34. doi:10.1074/jbc.M113.491928.

[29] Caillat C, Fish A, Pefani DE, Taraviras S, Lygerou Z, Perrakis A. The structure of the GemC1 coiled coil and its interaction with the Geminin family of coiled-coil proteins. Acta Crystallogr Sect D, Biol Crystallogr 2015;71:2278-86. doi:10.1107/S1399004715016892.

[30] Terré B, Piergiovanni G, Segura-Bayona S, Gil-Gómez G, Youssef SA, Attolini CS-O, et al. GEMC1 is a critical regulator of multiciliated cell differentiation. EMBO J 2016;35:942-60. doi:10.15252/embj.201592821.

[31] Lalioti M-E, Arbi M, Loukas I, Kaplani K, Kalogeropoulou A, Lokka G, et al. GemC1 governs multiciliogenesis through direct interaction with and transcriptional regulation of $\mathrm{p} 73$. J Cell Sci 2019;132. doi:10.1242/jcs.228684.

[32] Arbi M, Pefani D-E, Kyrousi C, Lalioti M-E, Kalogeropoulou A, Papanastasiou AD, et al. GemC1 controls multiciliogenesis in the airway epithelium. EMBO Rep 2016;17:400-13. doi:10.15252/embr.201540882.

[33] Kyrousi C, Arbi M, Pilz G-A, Pefani D-E, Lalioti M-E, Ninkovic J, et al. Mcidas and GemC1 are key regulators for the generation of multiciliated ependymal cells in the adult neurogenic niche. Development 2015;142:3661-74. doi:10.1242/dev.126342.

[34] Zhou F, Narasimhan V, Shboul M, Chong YL, Reversade B, Roy S. Gmnc is a master regulator of the multiciliated cell differentiation program. Curr Biol 2015;25:3267-73. doi:10.1016/j.cub.2015.10.062.

[35] Lu H, Anujan P, Zhou F, Zhang Y, Chong YL, Bingle CD, et al. Mcidas mutant mice reveal a two-step process for the specification and differentiation of multiciliated cells in mammals. Development 2019;146. doi:10.1242/dev.172643.

[36] Kim S, Ma L, Shokhirev MN, Quigley I, Kintner C. Multicilin and activated E2f4 induce multiciliated cell differentiation in primary fibroblasts. Sci Rep 2018;8:12369. doi:10.1038/s41598-018-30791-1.

[37] Stubbs JL, Vladar EK, Axelrod JD, Kintner C. Multicilin promotes centriole assembly and ciliogenesis during multiciliate cell differentiation. Nat Cell Biol 2012;14:140-7. 
doi:10.1038/ncb2406.

[38] Ma L, Quigley I, Omran H, Kintner C. Multicilin drives centriole biogenesis via E2f proteins. Genes Dev 2014;28:1461-71. doi:10.1101/gad.243832.114.

[39] Danielian PS, Bender Kim CF, Caron AM, Vasile E, Bronson RT, Lees JA. E2f4 is required for normal development of the airway epithelium. Dev Biol 2007;305:564-76. doi:10.1016/j.ydbio.2007.02.037.

[40] Lindeman GJ, Dagnino L, Gaubatz S, Xu Y, Bronson RT, Warren HB, et al. A specific, nonproliferative role for E2F-5 in choroid plexus function revealed by gene targeting. Genes Dev 1998;12:1092-8. doi:10.1101/gad.12.8.1092.

[41] Danielian PS, Hess RA, Lees JA. E2f4 and E2f5 are essential for the development of the male reproductive system. Cell Cycle 2016;15:250-60. doi:10.1080/15384101.2015.1121350.

[42] Fischer M, Müller GA. Cell cycle transcription control: DREAM/MuvB and RB-E2F complexes. Crit Rev Biochem Mol Biol 2017;52:638-62. doi:10.1080/10409238.2017.1360836.

[43] Chong YL, Zhang Y, Zhou F, Roy S. Distinct requirements of E2f4 versus E2f5 activity for multiciliated cell development in the zebrafish embryo. Dev Biol 2018;443:165-72. doi:10.1016/j.ydbio.2018.09.013.

[44] Seo S, Herr A, Lim J-W, Richardson GA, Richardson H, Kroll KL. Geminin regulates neuronal differentiation by antagonizing Brg1 activity. Genes Dev 2005;19:1723-34. doi:10.1101/gad.1319105.

[45] Sankar S, Yellajoshyula D, Zhang B, Teets B, Rockweiler N, Kroll KL. Gene regulatory networks in neural cell fate acquisition from genome-wide chromatin association of Geminin and Zic1. Sci Rep 2016;6:37412. doi:10.1038/srep37412.

[46] Karamitros D, Patmanidi AL, Kotantaki P, Potocnik AJ, Bähr-Ivacevic T, Benes V, et al. Geminin deletion increases the number of fetal hematopoietic stem cells by affecting the expression of key transcription factors. Development 2015;142:70-81. doi:10.1242/dev.109454.

[47] Nagl NG, Wang X, Patsialou A, Van Scoy M, Moran E. Distinct mammalian SWI/SNF chromatin remodeling complexes with opposing roles in cell-cycle control. EMBO J 2007;26:752-63. doi:10.1038/sj.emboj.7601541.

[48] Ortiz-Álvarez G, Daclin M, Shihavuddin A, Lansade P, Fortoul A, Faucourt M, et al. Adult neural stem cells and multiciliated ependymal cells share a common lineage regulated by the geminin family members. Neuron 2019;102:159-172.e7. doi:10.1016/j.neuron.2019.01.051.

[49] Pardo-Saganta A, Law BM, Tata PR, Villoria J, Saez B, Mou H, et al. Injury induces direct lineage segregation of functionally distinct airway basal stem/progenitor cell subpopulations. Cell Stem Cell 2015;16:184-97. doi:10.1016/j.stem.2015.01.002.

[50] Marques MM, Villoch-Fernandez J, Maeso-Alonso L, Fuertes-Alvarez S, Marin MC. The trp73 mutant mice: A ciliopathy model that uncouples ciliogenesis from planar cell polarity. Front Genet 2019;10:154. doi:10.3389/fgene.2019.00154.

[51] Nemajerova A, Kramer D, Siller SS, Herr C, Shomroni O, Pena T, et al. TAp73 is a central transcriptional regulator of airway multiciliogenesis. Genes Dev 2016;30:1300-12. doi:10.1101/gad.279836.116. 
[52] Marshall CB, Mays DJ, Beeler JS, Rosenbluth JM, Boyd KL, Santos Guasch GL, et al. p73 Is Required for Multiciliogenesis and Regulates the Foxj1-Associated Gene Network. Cell Rep 2016;14:2289-300. doi:10.1016/j.celrep.2016.02.035.

[53] Terré B, Lewis M, Gil-Gómez G, Han Z, Lu H, Aguilera M, et al. Defects in efferent duct multiciliogenesis underlie male infertility in GEMC1-, MCIDAS- or CCNO-deficient mice. Development 2019;146. doi:10.1242/dev.162628.

[54] Fujitani M, Sato R, Yamashita T. Loss of p73 in ependymal cells during the perinatal period leads to aqueductal stenosis. Sci Rep 2017;7:12007. doi:10.1038/s41598-017-12105-z.

[55] Gonzalez-Cano L, Fuertes-Alvarez S, Robledinos-Anton N, Bizy A, Villena-Cortes A, Fariñas I, et al. p73 is required for ependymal cell maturation and neurogenic SVZ cytoarchitecture. Dev Neurobiol 2016;76:730-47. doi:10.1002/dneu.22356.

[56] You Y, Huang T, Richer EJ, Schmidt J-EH, Zabner J, Borok Z, et al. Role of f-box factor foxj1 in differentiation of ciliated airway epithelial cells. Am J Physiol Lung Cell Mol Physiol 2004;286:L650-7. doi:10.1152/ajplung.00170.2003.

[57] Brody SL, Yan XH, Wuerffel MK, Song SK, Shapiro SD. Ciliogenesis and left-right axis defects in forkhead factor HFH-4-null mice. Am J Respir Cell Mol Biol 2000;23:45-51. doi:10.1165/ajrcmb.23.1.4070.

[58] Blatt EN, Yan XH, Wuerffel MK, Hamilos DL, Brody SL. Forkhead transcription factor HFH-4 expression is temporally related to ciliogenesis. Am J Respir Cell Mol Biol 1999;21:168-76. doi:10.1165/ajrcmb.21.2.3691.

[59] Okada A, Ohta Y, Brody SL, Watanabe H, Krust A, Chambon P, et al. Role of foxj1 and estrogen receptor alpha in ciliated epithelial cell differentiation of the neonatal oviduct. J Mol Endocrinol 2004;32:615-25. doi:10.1677/jme.0.0320615.

[60] Boon M, Wallmeier J, Ma L, Loges NT, Jaspers M, Olbrich H, et al. MCIDAS mutations result in a mucociliary clearance disorder with reduced generation of multiple motile cilia. Nat Commun 2014;5:4418. doi:10.1038/ncomms5418.

[61] Didon L, Zwick RK, Chao IW, Walters MS, Wang R, Hackett NR, et al. RFX3 modulation of FOXJ1 regulation of cilia genes in the human airway epithelium. Respir Res 2013;14:70. doi:10.1186/1465-9921-14-70.

[62] Jacquet BV, Salinas-Mondragon R, Liang H, Therit B, Buie JD, Dykstra M, et al. FoxJ1dependent gene expression is required for differentiation of radial glia into ependymal cells and a subset of astrocytes in the postnatal brain. Development 2009;136:4021-31. doi:10.1242/dev.041129.

[63] Newton FG, zur Lage PI, Karak S, Moore DJ, Göpfert MC, Jarman AP. Forkhead transcription factor $\mathrm{Fd} 3 \mathrm{~F}$ cooperates with $\mathrm{Rfx}$ to regulate a gene expression program for mechanosensory cilia specialization. Dev Cell 2012;22:1221-33. doi:10.1016/j.devcel.2012.05.010.

[64] Stubbs JL, Oishi I, Izpisúa Belmonte JC, Kintner C. The forkhead protein Foxj1 specifies node-like cilia in Xenopus and zebrafish embryos. Nat Genet 2008;40:1454-60. doi:10.1038/ng.267.

[65] Yu X, Ng CP, Habacher H, Roy S. Foxj1 transcription factors are master regulators of the motile ciliogenic program. Nat Genet 2008;40:1445-53. doi:10.1038/ng.263. 
[66] Quigley IK, Kintner C. Rfx2 stabilizes foxj1 binding at chromatin loops to enable multiciliated cell gene expression. PLoS Genet 2017;13:e1006538. doi:10.1371/journal.pgen.1006538.

[67] Abdi K, Lai C-H, Paez-Gonzalez P, Lay M, Pyun J, Kuo CT. Uncovering inherent cellular plasticity of multiciliated ependyma leading to ventricular wall transformation and hydrocephalus. Nat Commun 2018;9:1655. doi:10.1038/s41467-018-03812-w.

[68] Wallmeier J, Frank D, Shoemark A, Nöthe-Menchen T, Cindric S, Olbrich H, et al. De Novo Mutations in FOXJ1 Result in a Motile Ciliopathy with Hydrocephalus and Randomization of Left/Right Body Asymmetry. Am J Hum Genet 2019;105:1030-9. doi:10.1016/j.ajhg.2019.09.022.

[69] Campbell EP, Quigley IK, Kintner C. Foxn4 promotes gene expression required for the formation of multiple motile cilia. Development 2016;143:4654-64. doi:10.1242/dev.143859.

[70] Wang Z, Plasschaert LW, Aryal S, Renaud NA, Yang Z, Choo-Wing R, et al. TRRAP is a central regulator of human multiciliated cell formation. J Cell Biol 2018;217:1941-55. doi:10.1083/jcb.201706106.

[71] Filippakopoulos P, Picaud S, Mangos M, Keates T, Lambert J-P, Barsyte-Lovejoy D, et al. Histone recognition and large-scale structural analysis of the human bromodomain family. Cell 2012;149:214-31. doi:10.1016/j.cell.2012.02.013.

[72] Ciró M, Prosperini E, Quarto M, Grazini U, Walfridsson J, McBlane F, et al. ATAD2 is a novel cofactor for MYC, overexpressed and amplified in aggressive tumors. Cancer Res 2009;69:8491-8. doi:10.1158/0008-5472.CAN-09-2131.

[73] Rothhammer V, Quintana FJ. The aryl hydrocarbon receptor: an environmental sensor integrating immune responses in health and disease. Nat Rev Immunol 2019;19:184-97. doi:10.1038/s41577-019-0125-8.

[74] Villa M, Crotta S, Dingwell KS, Hirst EMA, Gialitakis M, Ahlfors H, et al. The aryl hydrocarbon receptor controls cyclin $\mathrm{O}$ to promote epithelial multiciliogenesis. Nat Commun 2016;7:12652. doi:10.1038/ncomms12652.

[75] Baba T, Shima Y, Owaki A, Mimura J, Oshima M, Fujii-Kuriyama Y, et al. Disruption of aryl hydrocarbon receptor (AhR) induces regression of the seminal vesicle in aged male mice. Sex Dev 2008;2:1-11. doi:10.1159/000117714.

[76] Johnson J-A, Watson JK, Nikolić MZ, Rawlins EL. Fank1 and Jazf1 promote multiciliated cell differentiation in the mouse airway epithelium. Biol Open 2018;7. doi:10.1242/bio.033944.

[77] Tadokoro T, Wang Y, Barak LS, Bai Y, Randell SH, Hogan BLM. IL-6/STAT3 promotes regeneration of airway ciliated cells from basal stem cells. Proc Natl Acad Sci USA 2014;111:E3641-9. doi:10.1073/pnas.1409781111.

[78] Nigg EA, Holland AJ. Once and only once: mechanisms of centriole duplication and their deregulation in disease. Nat Rev Mol Cell Biol 2018;19:297-312. doi:10.1038/nrm.2017.127.

[79] Bangs F, Anderson KV. Primary cilia and mammalian hedgehog signaling. Cold Spring Harb Perspect Biol 2017;9. doi:10.1101/cshperspect.a028175.

[80] Al Jord A, Lemaître A-I, Delgehyr N, Faucourt M, Spassky N, Meunier A. Centriole amplification by mother and daughter centrioles differs in multiciliated cells. Nature 
2014;516:104-7. doi:10.1038/nature13770.

[81] Zhao H, Zhu L, Zhu Y, Cao J, Li S, Huang Q, et al. The Cep63 paralogue Deup1 enables massive de novo centriole biogenesis for vertebrate multiciliogenesis. Nat Cell Biol 2013;15:1434-44. doi:10.1038/ncb2880.

[82] Klos Dehring DA, Vladar EK, Werner ME, Mitchell JW, Hwang P, Mitchell BJ. Deuterosome-mediated centriole biogenesis. Dev Cell 2013;27:103-12. doi:10.1016/j.devcel.2013.08.021.

[83] Zhang S, Mitchell BJ. Centriole biogenesis and function in multiciliated cells. Methods Cell Biol 2015;129:103-27. doi:10.1016/bs.mcb.2015.03.015.

[84] Revinski DR, Zaragosi L-E, Boutin C, Ruiz-Garcia S, Deprez M, Thomé V, et al. CDC20B is required for deuterosome-mediated centriole production in multiciliated cells. Nat Commun 2018;9:4668. doi:10.1038/s41467-018-06768-z.

[85] Nanjundappa R, Kong D, Shim K, Stearns T, Brody SL, Loncarek J, et al. Regulation of cilia abundance in multiciliated cells. Elife 2019;8. doi:10.7554/eLife.44039.

[86] Zhao H, Chen Q, Fang C, Huang Q, Zhou J, Yan X, et al. Parental centrioles are dispensable for deuterosome formation and function during basal body amplification. EMBO Rep 2019;20. doi:10.15252/embr.201846735.

[87] Mercey O, Al Jord A, Rostaing P, Mahuzier A, Fortoul A, Boudjema A-R, et al. Dynamics of centriole amplification in centrosome-depleted brain multiciliated progenitors. Sci Rep 2019;9:13060. doi:10.1038/s41598-019-49416-2.

[88] Mori M, Hazan R, Danielian PS, Mahoney JE, Li H, Lu J, et al. Cytoplasmic E2f4 forms organizing centres for initiation of centriole amplification during multiciliogenesis. Nat Commun 2017;8:15857. doi:10.1038/ncomms15857.

[89] Al Jord A, Shihavuddin A, Servignat d'Aout R, Faucourt M, Genovesio A, Karaiskou A, et al. Calibrated mitotic oscillator drives motile ciliogenesis. Science 2017;358:803-6. doi:10.1126/science.aan8311.

[90] Vladar EK, Stratton MB, Saal ML, Salazar-De Simone G, Wang X, Wolgemuth D, et al. Cyclin-dependent kinase control of motile ciliogenesis. Elife 2018;7. doi:10.7554/eLife.36375.

[91] Funk MC, Bera AN, Menchen T, Kuales G, Thriene K, Lienkamp SS, et al. Cyclin O (Ccno) functions during deuterosome-mediated centriole amplification of multiciliated cells. EMBO J 2015;34:1078-89. doi:10.15252/embj.201490805.

[92] Núnez-Ollé M, Jung C, Terré B, Balsiger NA, Plata C, Roset R, et al. Constitutive Cyclin O deficiency results in penetrant hydrocephalus, impaired growth and infertility. Oncotarget 2017;8:99261-73. doi:10.18632/oncotarget.21818.

[93] Marjanović M, Sánchez-Huertas C, Terré B, Gómez R, Scheel JF, Pacheco S, et al. CEP63 deficiency promotes p53-dependent microcephaly and reveals a role for the centrosome in meiotic recombination. Nat Commun 2015;6:7676. doi:10.1038/ncomms8676.

[94] Mercey O, Levine MS, LoMastro GM, Rostaing P, Brotslaw E, Gomez V, et al. Massive centriole production can occur in the absence of deuterosomes in multiciliated cells. Nat Cell Biol 2019;21:1544-52. doi:10.1038/s41556-019-0427-x. 
loss in the evolution of planarians. Science 2012;335:461-3. doi:10.1126/science.1214457.

[96] Kramer-Zucker AG, Olale F, Haycraft CJ, Yoder BK, Schier AF, Drummond IA. Cilia-driven fluid flow in the zebrafish pronephros, brain and Kupffer's vesicle is required for normal organogenesis. Development 2005;132:1907-21. doi:10.1242/dev.01772.

[97] Kemp A. Role of epidermal cilia in development of the Australian lungfish, Neoceratodus forsteri (Osteichthyes: Dipnoi). J Morphol 1996;228:203-21. doi:10.1002/(SICI)10974687(199605)228:2<203::AID-JMOR9>3.0.CO;2-5.

[98] Ito D, Zitouni S, Jana SC, Duarte P, Surkont J, Carvalho-Santos Z, et al. Pericentrin-mediated SAS-6 recruitment promotes centriole assembly. Elife 2019;8. doi:10.7554/eLife.41418.

[99] Butler MT, Wallingford JB. Planar cell polarity in development and disease. Nat Rev Mol Cell Biol 2017;18:375-88. doi:10.1038/nrm.2017.11.

[100] Stubbs JL, Davidson L, Keller R, Kintner C. Radial intercalation of ciliated cells during Xenopus skin development. Development 2006;133:2507-15. doi:10.1242/dev.02417.

[101] Walck-Shannon E, Hardin J. Cell intercalation from top to bottom. Nat Rev Mol Cell Biol 2014;15:34-48. doi:10.1038/nrm3723.

[102] Sirour C, Hidalgo M, Bello V, Buisson N, Darribère T, Moreau N. Dystroglycan is involved in skin morphogenesis downstream of the Notch signaling pathway. Mol Biol Cell 2011;22:2957-69. doi:10.1091/mbc.E11-01-0074.

[103] Kim K, Lake BB, Haremaki T, Weinstein DC, Sokol SY. Rab11 regulates planar polarity and migratory behavior of multiciliated cells in Xenopus embryonic epidermis. Dev Dyn 2012;241:1385-95. doi:10.1002/dvdy.23826.

[104] Werner ME, Mitchell JW, Putzbach W, Bacon E, Kim SK, Mitchell BJ. Radial intercalation is regulated by the Par complex and the microtubule-stabilizing protein CLAMP/Spef1. J Cell Biol 2014;206:367-76. doi:10.1083/jcb.201312045.

[105] Chung M-I, Kwon T, Tu F, Brooks ER, Gupta R, Meyer M, et al. Coordinated genomic control of ciliogenesis and cell movement by RFX2. Elife 2014;3:e01439. doi:10.7554/eLife.01439.

[106] Sedzinski J, Hannezo E, Tu F, Biro M, Wallingford JB. RhoA regulates actin network dynamics during apical surface emergence in multiciliated epithelial cells. J Cell Sci 2017;130:420-8. doi:10.1242/jcs. 194704.

[107] Chung M-I, Peyrot SM, LeBoeuf S, Park TJ, McGary KL, Marcotte EM, et al. RFX2 is broadly required for ciliogenesis during vertebrate development. Dev Biol 2012;363:155-65. doi:10.1016/j.ydbio.2011.12.029.

[108] Bisgrove BW, Makova S, Yost HJ, Brueckner M. RFX2 is essential in the ciliated organ of asymmetry and an RFX2 transgene identifies a population of ciliated cells sufficient for fluid flow. Dev Biol 2012;363:166-78. doi:10.1016/j.ydbio.2011.12.030.

[109] Kistler WS, Baas D, Lemeille S, Paschaki M, Seguin-Estevez Q, Barras E, et al. RFX2 is a major transcriptional regulator of spermiogenesis. PLoS Genet 2015;11:e1005368. doi:10.1371/journal.pgen.1005368.

[110] Wu Y, Hu X, Li Z, Wang M, Li S, Wang X, et al. Transcription factor RFX2 is a key regulator of mouse spermiogenesis. Sci Rep 2016;6:20435. doi:10.1038/srep20435. 
[111] Shawlot W, Vazquez-Chantada M, Wallingford JB, Finnell RH. Rfx2 is required for spermatogenesis in the mouse. Genesis 2015;53:604-11. doi:10.1002/dvg.22880.

[112] Sedzinski J, Hannezo E, Tu F, Biro M, Wallingford JB. Emergence of an apical epithelial cell surface in vivo. Dev Cell 2016;36:24-35. doi:10.1016/j.devcel.2015.12.013.

[113] Zhao R, Fallon TR, Saladi SV, Pardo-Saganta A, Villoria J, Mou H, et al. Yap tunes airway epithelial size and architecture by regulating the identity, maintenance, and self-renewal of stem cells. Dev Cell 2014;30:151-65. doi:10.1016/j.devcel.2014.06.004.

[114] Kim J, Jo H, Hong H, Kim MH, Kim JM, Lee J-K, et al. Actin remodelling factors control ciliogenesis by regulating YAP/TAZ activity and vesicle trafficking. Nat Commun 2015;6:6781. doi:10.1038/ncomms7781.

[115] Tu F, Sedzinski J, Ma Y, Marcotte EM, Wallingford JB. Protein localization screening in vivo reveals novel regulators of multiciliated cell development and function. J Cell Sci 2018;131. doi:10.1242/jcs.206565.

[116] Kim HY, Jackson TR, Stuckenholz C, Davidson LA. Tissue mechanics drives regeneration of a mucociliated epidermis on the surface of Xenopus embryonic aggregates. Nat Commun 2020;11:665. doi:10.1038/s41467-020-14385-y.

[117] van Soldt BJ, Qian J, Li J, Tang N, Lu J, Cardoso WV. Yap and its subcellular localization have distinct compartment-specific roles in the developing lung. Development 2019;146. doi:10.1242/dev.175810.

[118] Miyatake K, Kusakabe M, Takahashi C, Nishida E. ERK7 regulates ciliogenesis by phosphorylating the actin regulator CapZIP in cooperation with Dishevelled. Nat Commun 2015;6:6666. doi:10.1038/ncomms7666.

[119] Epting D, Slanchev K, Boehlke C, Hoff S, Loges NT, Yasunaga T, et al. The Rac1 regulator ELMO controls basal body migration and docking in multiciliated cells through interaction with Ezrin. Development 2015;142:174-84. doi:10.1242/dev.112250.

[120] Gomperts BN, Gong-Cooper X, Hackett BP. Foxj1 regulates basal body anchoring to the cytoskeleton of ciliated pulmonary epithelial cells. J Cell Sci 2004;117:1329-37. doi: $10.1242 /$ jcs.00978.

[121] Pan J, You Y, Huang T, Brody SL. RhoA-mediated apical actin enrichment is required for ciliogenesis and promoted by Foxj1. J Cell Sci 2007;120:1868-76. doi:10.1242/jcs.005306.

[122] Kulkarni SS, Griffin JN, Date PP, Liem KF, Khokha MK. WDR5 stabilizes actin architecture to promote multiciliated cell formation. Dev Cell 2018;46:595-610.e3. doi:10.1016/j.devcel.2018.08.009.

[123] Fuertes-Alvarez S, Maeso-Alonso L, Villoch-Fernandez J, Wildung M, Martin-Lopez M, Marshall C, et al. p73 regulates ependymal planar cell polarity by modulating actin and microtubule cytoskeleton. Cell Death Dis 2018;9:1183. doi:10.1038/s41419-018-1205-6.

[124] Vladar EK, Nayak JV, Milla CE, Axelrod JD. Airway epithelial homeostasis and planar cell polarity signaling depend on multiciliated cell differentiation. JCI Insight 2016.

[125] Tissir F, Qu Y, Montcouquiol M, Zhou L, Komatsu K, Shi D, et al. Lack of cadherins Celsr2 and Celsr3 impairs ependymal ciliogenesis, leading to fatal hydrocephalus. Nat Neurosci 2010;13:700-7. doi:10.1038/nn.2555.

[126] Park TJ, Mitchell BJ, Abitua PB, Kintner C, Wallingford JB. Dishevelled controls apical 
docking and planar polarization of basal bodies in ciliated epithelial cells. Nat Genet 2008;40:871-9. doi:10.1038/ng.104.

[127] Tan FE, Vladar EK, Ma L, Fuentealba LC, Hoh R, Espinoza FH, et al. Myb promotes centriole amplification and later steps of the multiciliogenesis program. Development 2013;140:4277-86. doi:10.1242/dev.094102.

[128] El Zein L, Ait-Lounis A, Morlé L, Thomas J, Chhin B, Spassky N, et al. RFX3 governs growth and beating efficiency of motile cilia in mouse and controls the expression of genes involved in human ciliopathies. J Cell Sci 2009;122:3180-9. doi:10.1242/jcs.048348.

[129] Pan J-H, Adair-Kirk TL, Patel AC, Huang T, Yozamp NS, Xu J, et al. Myb permits multilineage airway epithelial cell differentiation. Stem Cells 2014;32:3245-56. doi:10.1002/stem.1814.

[130] Wallmeier J, Al-Mutairi DA, Chen C-T, Loges NT, Pennekamp P, Menchen T, et al. Mutations in CCNO result in congenital mucociliary clearance disorder with reduced generation of multiple motile cilia. Nat Genet 2014;46:646-51. doi:10.1038/ng.2961.

[131] Amirav I, Wallmeier J, Loges NT, Menchen T, Pennekamp P, Mussaffi H, et al. Systematic analysis of CCNO variants in a defined population: implications for clinical phenotype and differential diagnosis. Hum Mutat 2016;37:396-405. doi:10.1002/humu.22957.

[132] Núnez-Ollé M, Stracker TH, Gil-Gómez G. CCNO mutations in NPH? Aging (Albany, NY) 2018;10:158-9. doi:10.18632/aging.101379.

[133] Zhang X, Jia S, Chen Z, Chong YL, Xie H, Feng D, et al. Cilia-driven cerebrospinal fluid flow directs expression of urotensin neuropeptides to straighten the vertebrate body axis. Nat Genet 2018;50:1666-73. doi:10.1038/s41588-018-0260-3.

[134] Lalioti M-E, Kaplani K, Lokka G, Georgomanolis T, Kyrousi C, Dong W, et al. GemC1 is a critical switch for neural stem cell generation in the postnatal brain. Glia 2019. doi:10.1002/glia.23690.

[135] Chivukula RR, Montoro DT, Leung HM, Yang J, Shamseldin HE, Taylor MS, et al. A human ciliopathy reveals essential functions for NEK10 in airway mucociliary clearance. Nat Med 2020. doi:10.1038/s41591-019-0730-x.

[136] Sugiyama M, Sakaue-Sawano A, Iimura T, Fukami K, Kitaguchi T, Kawakami K, et al. Illuminating cell-cycle progression in the developing zebrafish embryo. Proc Natl Acad Sci USA 2009;106:20812-7. doi:10.1073/pnas.0906464106.

[137] Burrage LC, Charng W-L, Eldomery MK, Willer JR, Davis EE, Lugtenberg D, et al. De Novo GMNN Mutations Cause Autosomal-Dominant Primordial Dwarfism Associated with Meier-Gorlin Syndrome. Am J Hum Genet 2015;97:904-13. doi:10.1016/j.ajhg.2015.11.006.

[138] Li L, Cao Y, Zhou H, Li Y, He B, Zhou X, et al. Knockdown of CCNO decreases the tumorigenicity of gastric cancer by inducing apoptosis. Onco Targets Ther 2018;11:7471-81. doi:10.2147/OTT.S176252.

[139] Cerami E, Gao J, Dogrusoz U, Gross BE, Sumer SO, Aksoy BA, et al. The cBio cancer genomics portal: an open platform for exploring multidimensional cancer genomics data. Cancer Discov 2012;2:401-4. doi:10.1158/2159-8290.CD-12-0095.

[140] Gao J, Aksoy BA, Dogrusoz U, Dresdner G, Gross B, Sumer SO, et al. Integrative analysis of complex cancer genomics and clinical profiles using the cBioPortal. Sci Signal 2013;6:pl1. 
doi:10.1126/scisignal.2004088.

[141] Roset R, Gil-Gómez G. Measurement of changes in Cdk2 and cyclin o-associated kinase activity in apoptosis. Methods Mol Biol 2009;559:161-72. doi:10.1007/978-1-60327-0175_12.

[142] Hoh RA, Stowe TR, Turk E, Stearns T. Transcriptional program of ciliated epithelial cells reveals new cilium and centrosome components and links to human disease. PLoS One 2012;7:e52166. doi:10.1371/journal.pone.0052166.

[143] Ruiz García S, Deprez M, Lebrigand K, Cavard A, Paquet A, Arguel M-J, et al. Novel dynamics of human mucociliary differentiation revealed by single-cell RNA sequencing of nasal epithelial cultures. Development 2019;146. doi:10.1242/dev.177428.

[144] Chu Q, Yao C, Qi X, Stripp BR, Tang N. STK11 is required for the normal program of ciliated cell differentiation in airways. Cell Discov 2019;5:36. doi:10.1038/s41421-019-0104$\mathrm{z}$. 